\title{
Quadricuspid pulmonary valve and left pulmonary artery aneurysm in an asymptomatic patient assessed by cardiovascular MRI
}

\author{
G. J. Nollen • J. Kodde • A. M. Beek • J. C. J. Res • \\ A. C. van Rossum
}

Published online: 20 April 2011

(C) The Author(s) 2011. This article is published with open access at Springerlink.com

\begin{abstract}
We present a coincidental finding of quadricuspid pulmonary valve and left pulmonary artery aneurysm. As both the pulmonary valve and the pulmonary trunk with its main branches are hard to visualise with cardiac ultrasound, most abnormalities described so far are from autopsy series. With the increasing use of CMR and its excellent potential for visualising both pulmonary valve and pulmonary arteries, we believe more cases will be discovered in the near future. Although pulmonary artery aneurysm are rare, timely detection may prevent lethal bleeding.
\end{abstract}

Keywords Magnetic resonance imaging · Pulmonary valve $\cdot$ Pulmonary artery

A 58-year-old man was seen in our outpatient clinic after an uncomplicated ablation procedure of an AV nodal re-entry tachycardia. A routine chest X-ray revealed a dilated left pulmonary artery (Fig. 1). Physical examination was normal. Transthoracic echocardiography showed normalsized cardiac chambers and normal systolic function of both

Electronic supplementary material The online version of this article (doi:10.1007/s12471-011-0115-3) contains supplementary material, which is available to authorized users.

G. J. Nollen $(\bowtie) \cdot$ J. Kodde $\cdot$ A. M. Beek · J. C. J. Res •

A. C. van Rossum

Department of Cardiology, VU Medical Center,

De Boelelaan 1117,

$1081 \mathrm{HV}$, Amsterdam, the Netherlands

e-mail: gj.nollen@ikazia.nl

Present Address:

G. J. Nollen

Ikazia Hospital,

Montessoriweg 1,

3083 AN, Rotterdam, the Netherlands ventricles. The main pulmonary artery had a normal diameter; however, the left and right pulmonary arteries could not be visualised. Using cardiac catheterisation, pulmonary artery hypertension was ruled out. Cardiovascular magnetic resonance imaging (CMR) demonstrated an aneurysm of the left pulmonary artery with a diameter of $47 \mathrm{~mm}$, and normal diameters of the main and right pulmonary artery (24 $\mathrm{mm}$ and $20 \mathrm{~mm}$, respectively) (Fig. 2). Furthermore a quadricuspid pulmonary valve was found with no significant stenosis and mild to moderate regurgitation (Fig. 3, Movie I-III).

Quadricuspid pulmonary valves are found in 1:250 to 1:2,500 autopsies and may be associated with other

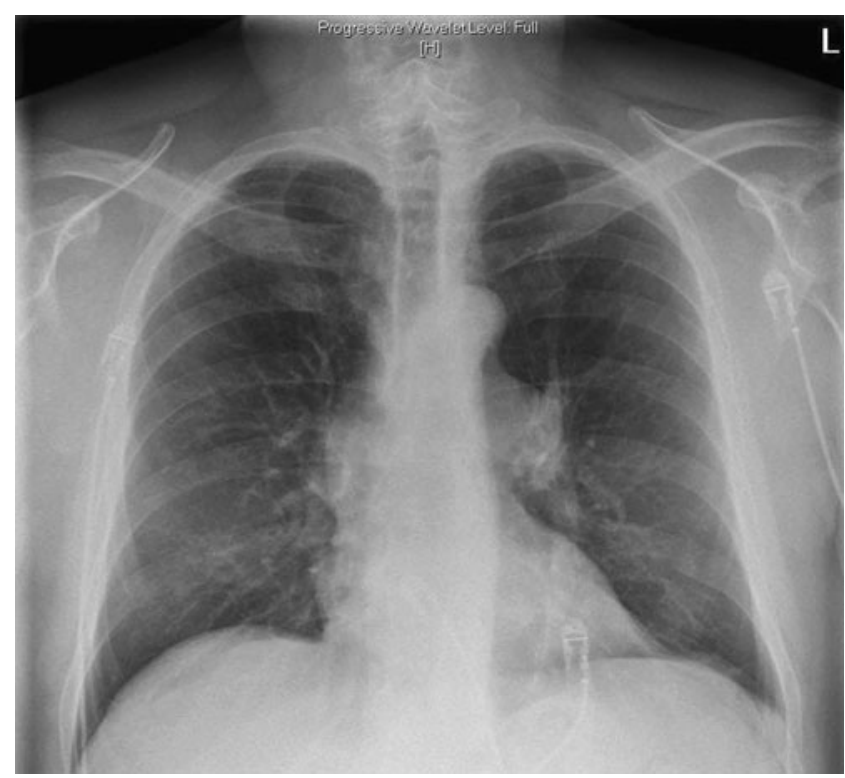

Fig. 1 Chest radiography in the anteroposterior view showing a dilated left pulmonary artery 

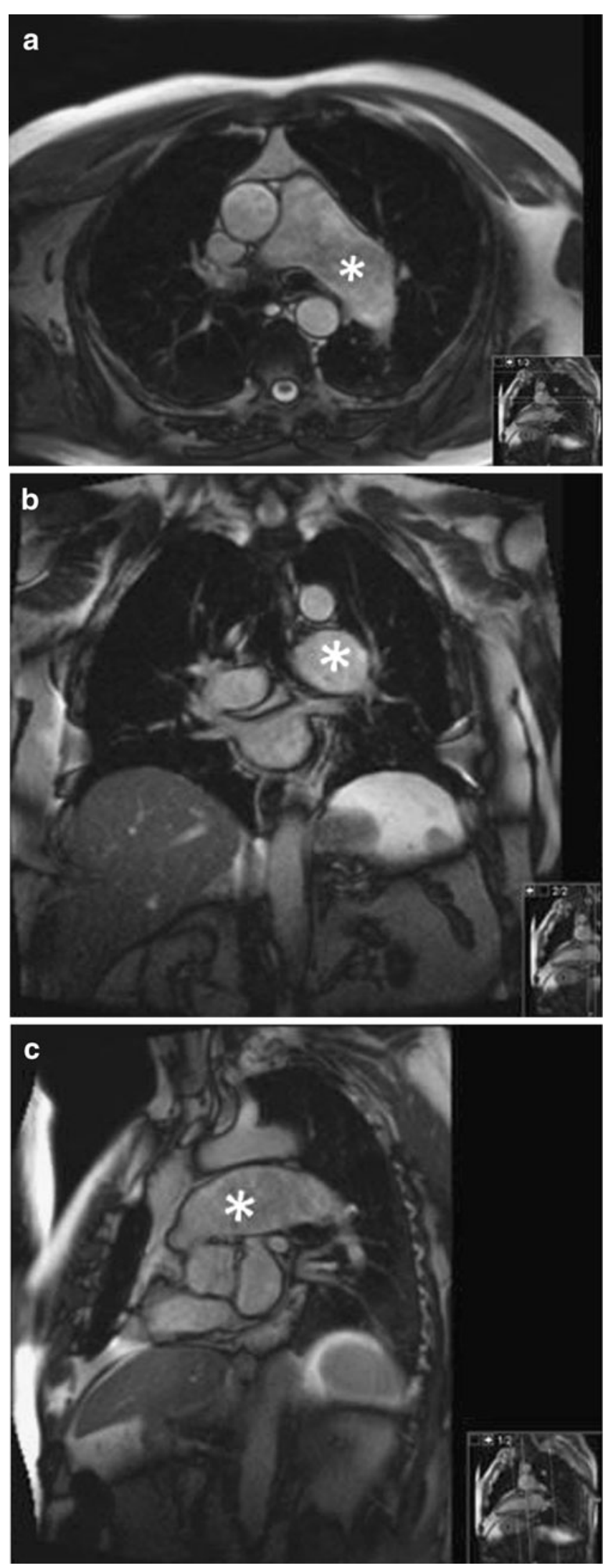

Fig. 2 Cardiac magnetic resonance imaging with balanced steadystate free precession sequence showing a dilated left pulmonary artery (asterisk) in axial a, coronal b, and oblique sagittal $\mathbf{c}$ view

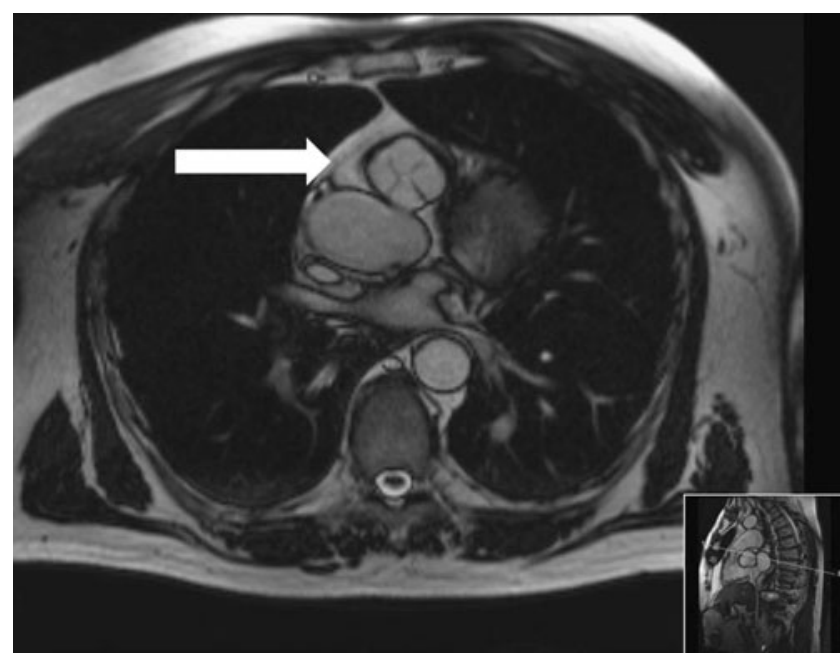

Fig. 3 Cardiac magnetic resonance imaging with balanced steadystate free precession sequence showing quadricuspid pulmonary valve (arrow)

congenital abnormalities, as patent ductus arteriosus, atrial or ventricular septal defects or aortic valve abnormalities [1]. Quadricuspid pulmonary valves predominate in males and are more frequently found than quadricuspid aortic valves (with a ratio of $2: 1$, and 9:1, respectively) [2]. A quadricuspid pulmonary valve is usually clinically quiescent, and significant valvular stenosis or regurgitation rarely occur [3].

Aneurysm of the pulmonary arteries are also rare, found in approximately 1:14,000 autopsies [4]. Of these aneurysms $80 \%$ are located in the main pulmonary artery. Gender distribution is equal. Congenital structural heart disease (patent ductus arteriosus, atrial or ventricular septal defects, pulmonary valve stenosis) accounts for $50 \%$ of the cases of pulmonary artery aneurysm [5]. Other causes are infections (tuberculosis, mycotic infections or syphilis), connective tissue disorders (Marfan, Ehlers-Danlos), Behcets syndrome, pulmonary hypertension, atherosclerosis or trauma. In a minority of cases, no cause is identified. Local compression on adjacent structures may produce symptoms of thoracic pain, dyspnoea or cough. Rupture of the aneurysm may lead to (fatal) haemoptysis. Management of pulmonary artery aneurysm remains controversial. Early surgery has been suggested in case of symptoms or large aneurysms, especially mycotic aneurysms, which tend to rupture earlier. In idiopathic aneurysm a more conservative strategy has been advocated, as these have a lower tendency to rupture [6].

In our patient no possible causes for the aneurysm and no other congenital abnormalities were found, and it was considered idiopathic. A follow-up CMR will be performed in 6 months. To our best knowledge, only one case of quadricuspid pulmonary valve in combination with an 
idiopathic pulmonary artery aneurysm has been described previously [7]. In that case the aneurysm was located in the main pulmonary artery.

As both the pulmonary valve and the pulmonary trunk with its main branches are hard to visualise with cardiac ultrasound, most abnormalities described so far are from autopsy series. With the increasing use of CMR and its excellent potential of visualising both the pulmonary valve and pulmonary arteries, we believe more cases will be discovered in the near future. Although pulmonary artery aneurysms are rare, timely detection may prevent lethal bleeding.

\section{Consent}

Informed consent was obtained from the patient for publication of this case report and accompanying images. A copy of the written consent is available for review by the editor in chief of this journal.
Open Access This article is distributed under the terms of the Creative Commons Attribution Noncommercial License which permits any noncommercial use, distribution, and reproduction in any medium, provided the original author(s) and source are credited.

\section{References}

1. Davia JE, Fenoglio JJ, DeCastro CM, et al. Quadricuspid semilunar valves. Chest. 1977;72:186-9.

2. Fernandez-Armenta J, Villagomez D, Fernandez-Vivancos C, et al. Quadricuspid pulmonary valve identified by transthoracic echocardiography. Echocardiography. 2009;26:288-90.

3. Enoch BA. Quadricuspid pulmonary valve. Br Heart J. 1968;30:67-9.

4. Deterling RA, Clagett OT. Aneurysm of the pulmonary artery: review of the literature and report of a case. Am Heart J. 1947;34:471-99.

5. Shih HH, Kang PL, Lin CY, et al. Main pulmonary artery aneurysm. J Chin Med Assoc. 2007;70:453-5.

6. Nair KKS, Cobanoglu AM. Idiopathic main pulmonary artery aneurysm. Ann Thorac Surg. 2001;71:1688-90.

7. Delicia I, Lorente G. The pulmonary valve and the pulmonary artery. Eur Heart J. 2009;30:2326. 